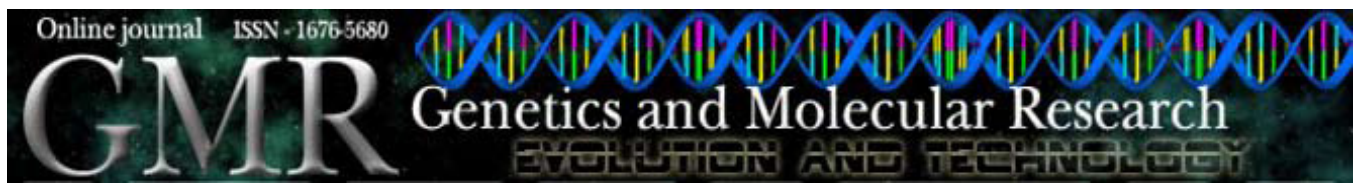

\title{
Heat and chemical stress modulate the expression of the $\alpha-R Y R$ gene in broiler chickens
}

\author{
I.L. Ziober ${ }^{1}$, F.G. Paião ${ }^{1}$, D.F. Marchi ${ }^{1}$, L.L. Coutinho ${ }^{2}$, E. Binneck ${ }^{3}$, \\ A.L. Nepomuceno ${ }^{3}$ and M. Shimokomaki ${ }^{1}$ \\ ${ }^{1}$ Departamento de Ciência e Tecnologia de Alimentos, \\ Universidade Estadual de Londrina, Londrina, PR, Brasil \\ ${ }^{2}$ Laboratório de Biotecnologia Animal, \\ Escola Superior de Agricultura "Luiz de Queiróz", \\ Universidade de São Paulo, Piracicaba, SP, Brasil \\ ${ }^{3}$ Laboratório de Biotecnologia Vegetal, \\ Empresa Brasileira de Pesquisa Agropecuária-Soja, Londrina, PR, Brasil \\ Corresponding author: M. Shimokomaki \\ E-mail: mshimo@uel.br
}

Genet. Mol. Res. 9 (2): 1258-1266 (2010)

Received March 5, 2010

Accepted April 5, 2010

Published June 29, 2010

DOI 10.4238/vol9-2gmr830

ABSTRACT. The biological cause of Pork Stress syndrome, which
leads to PSE (pale, soft, exudative) meat, is excessive release of $\mathrm{Ca}^{2+}$
ions, which is promoted by a genetic mutation in the ryanodine receptors
(RyR) located in the sarcoplasmic reticulum of the skeletal muscle cells.
We examined the relationship between the formation of PSE meat under
halothane treatment and heat stress exposure in chicken $\alpha \mathrm{RYR}$ hot spot
fragments. Four test groups were compared: 1) birds slaughtered without
any treatment, i.e., the control group (C); 2) birds slaughtered immediately
after halothane treatment (H); 3) birds slaughtered immediately after
heat stress treatment (HS), and 4) birds exposed to halothane and to heat
stress (H+HS), before slaughtering. Breast muscle mRNA was extracted,
amplified by RT-PCR, and sequenced. PSE meat was evaluated using
color determination (L* value). The most common alteration was deletion
of a single nucleotide, which generated a premature stop codon, resulting
in the production of truncated proteins. The highest incidence of nonsense
transcripts came with exposure to halothane; $80 \%$ of these abnormal 
transcripts were detected in $\mathrm{H}$ and $\mathrm{H}+\mathrm{HS}$ groups. As a consequence, the incidence of abnormal meat was highest in the H+HS group (66\%). In $\mathrm{HS}, \mathrm{H}$, and $\mathrm{C}$ groups, PSE meat developed in 60,50 , and $33 \%$ of the samples, respectively. Thus, halothane apparently modulates $\alpha$ RYR gene expression in this region, and synergically with exposure to heat stress, causes Avian Stress syndrome, resulting in PSE meat in broiler chickens.

Key words: PSE (pale, soft, exudative) meat; Abnormal meat color; Ryanodine receptor

\section{INTRODUCTION}

The ryanodine receptor (RyR) is a homotetrameric $\mathrm{Ca}^{2+}$ release channel in the sarcoplasmic reticulum that provides the $\mathrm{Ca}^{2+}$ necessary for the contraction of cardiac and skeletal muscle cells in mammals (Sutko and Airey, 1996; MacLennan, 2000). In mammals there are three isoforms of RyR: RyR1, RyR2 and RyR3. The presence of a particular isoform depends on the nature of the tissues or organs. Two RyRs are co-expressed in the same ratio in avian, amphibian and piscine fast twitch skeletal muscles. These two isoforms, homologous to RyR1 and RyR3, are named $\alpha$-RyR and $\beta$-RyR, respectively (Sutko and Airey, 1996; Rossi and Sorrentino, 2004). The schematic of muscle excitation in Figure 1 shows the $\alpha$-RyR and $\beta$-RyR isoforms. Recently, reported results from our laboratory suggested that an alteration in the ratio $(1: 1)$ of $\alpha-R Y R / \beta-$ RYR in favor of $\alpha$-RYR was found in broiler PSE (pale, soft, exudative) meat (Oda et al., 2009).

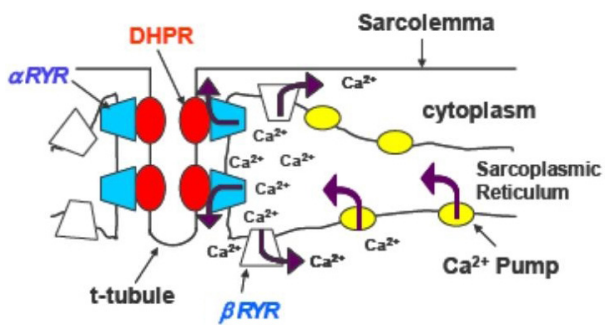

Figure 1. Schematic diagram of the mechanism of excitation-contraction in the skeletal muscle of birds. The t-tubule depolarization causes $\mathrm{Ca}^{2+}$ release by $\alpha \mathrm{RYR}$ that is physically coupled to the dihydropyridine receptor (DHPR) (shown in red). The increased local concentration of $\mathrm{Ca}^{2+}$ causes the opening of the $\beta R Y R$ (shown in white) that is located peripherally to t-tubules/junction of the SR (sarcoplasmic reticulum). The calcium ions are recaptured during muscle relaxation by the calcium pump (shown in yellow). Adapted from Strasburg and Chiang (2003).

A point mutation in the RYR1 gene $\left(\mathrm{C}^{1843} \rightarrow \mathrm{T}\right)$ leads to a health problem known as Pork Stress syndrome (PSS) and consequently to the development of PSE meat causing serious economic losses to the pork industry (Fujii et al., 1991). In humans, a mutation at the same region of this gene (hotspot 1) promotes a reaction towards the anesthetic halothane, known as malignant hyperthermia (Brini, 2004). The genetic origin of pork PSE meat has been described as a biochemically stimulated continuous opening of the RyR1 channel. In the affected meat, the channel opening is favored and its closure is inhibited. In mutated animals that are subjected to physiological stress, an accumulation of intracellular calcium occurs and consequently, a continuous muscle contraction takes place accelerating the glycolysis reaction and producing more lactic acid, which subsequently leads to PSS 
formation (Fujii et al., 1991). The identification of this mutation provided a biochemical and physiological explanation for the origin of PSS and the occurrence of PSE meat in pork. An understanding of this system has been the basis for the initiation of breeding strategies to eliminate the mutation from global pig populations as well as pig populations in Brazil (Band et al., 2005).

The causes and consequences of broiler breast PSE meat have recently been the subject of experimental studies by several research groups (Olivo and Shimokomaki, 2006; Barbut et al., 2008; Swatland, 2008). The addition of vitamin E to the birds' diet successfully reduced the formation of PSE meat (Olivo et al., 2001) and increased phospholipase $\mathrm{A}_{2}$ activity (Soares et al., 2003), which may enhance lipid oxidation in PSE meat (Soares et al., 2009). Showering just before slaughtering at processing plants calms the birds and contributes to $\mathrm{Ca}^{2+}$ homeostasis (Guarnieri et al., 2004). Transportation conditions between the farm and abattoir can influence the formation of PSE meat (Mitchell and Kettlewell, 1998; Simões et al., 2009a; Langer, 2010). Ultrastructural studies have revealed that a robust sarcomere shrinking within the muscle fibrils takes place in PSE (Guarnieri et al., 2004; Barbut et al., 2005). There is growing evidence that the exposure of birds to thermal stress just before sacrifice is one of the causes of PSE meat (Barbut, 1998; Mitchell and Kettlewell, 1998; Simões et al., 2009b). Ultra-structural studies have also revealed that a robust sarcomere shortage occurs within the muscle fibrils in PSE meat (Barbut et al., 2005; Wilhelm et al., 2010). There is growing evidence that birds exposed to thermal stress conditions just before slaughter have a higher occurrence of PSE meat (Barbut, 1998; Simões et al., 2009b). Although PSE meat occurs in turkeys and chickens in a manner that is similar to pigs, a mutation in the RYR gene responsible for this problem has not yet been found in birds. In turkeys, Chiang et al. (2004) reported that changes in the hotspot 1 region of the $\alpha \mathrm{RYR}$ mRNA were related to the occurrence of PSE meat. This region corresponds to the N-terminal portion of the protein and some reports indicate that it is an important regulatory domain for controlling the sensitivity of the channel protein and the release of $\mathrm{Ca}^{2+}$ (Brini, 2004; Strasburg and Chiang, 2009) (Figure 2).

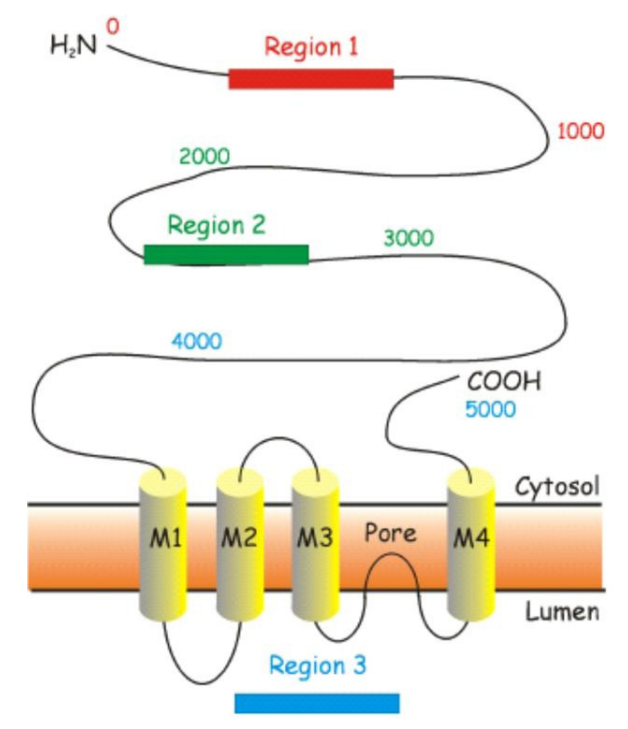

Figure 2. Schematic diagram for the location of the hotspot regions (1-3) and the predicted transmembrane domain (M1-M4) of RYR1. Adapted from Brini (2004). 
In broilers, this hotspot region was first sequenced and identified in our lab (Ziober et al., 2009). The aim of this study was to evaluate the correlation between birds subjected to both halothane treatment and heat stress conditions to mutations in the hotspot 1 of $\alpha \mathrm{RYR}$ transcripts leading possibly to the Avian Stress syndrome.

\section{MATERIAL AND METHODS}

Aged broilers of 44 days of commercial lineage $(\mathrm{N}=18)$ were raised according to traditional methods. These birds were exposed to halothane in a special experimental anesthetic chamber designed in our laboratory (Marchi et al., 2009). Each experimental treatment consisted of three birds that were accommodated in the three-hole chamber. The birds were anesthetized with $3.0 \%$ halothane in pure oxygen at a flow rate of $6.0 \mathrm{~L} / \mathrm{min}$ for $5 \mathrm{~min}$. Ten birds were exposed to halothane and four of them were slaughtered immediately (H group). The remaining six birds were subsequently subjected to a heat stress chamber ( $\mathrm{H}+\mathrm{HS}$ group). The thermal stress condition was applied by placing the birds in a closed room under a constant temperature of $35^{\circ} \mathrm{C}$ for $1 \mathrm{~h}$. The birds were slaughtered immediately following heat stress.

The control group consisted of three birds that were not exposed to either halothane or to the heat stress (C group). In order to evaluate the effects of heat stress, the last group of five birds was exposed only to the heat stress and not to halothane (HS group). The slaughtering process was carried out under laboratory conditions by cutting the carotid artery and the jugular vein without prior electrical stunning. The muscle samples $\left(0.5 \times 2.0 \times 1.0 \mathrm{~cm}^{3}\right)$ were collected immediately after bleeding and placed in microtubes $(1.5 \mathrm{~mL})$ after which they were quickly frozen in liquid nitrogen and stored at $-80^{\circ} \mathrm{C}$. Total RNA was extracted from the pectoralis major muscle according to Chomczynski and Sacchi (1987). cDNA was obtained through reverse transcription with SuperScript III RNase $\mathrm{H}^{-}$Reverse Transcriptase (Invitrogen, Carlsbad, CA, USA), following manufacturer instructions.

The primers used for polymerase chain reaction (PCR) amplification were the same as those used by Chiang et al. (2004) for turkeys (Meleagris gallopavo) and had the following sequences: 5'-CTG CAC CAG GAG GGC CAC ATG GAC GA-3' (forward) and 5'-CGG TCC AGT TTG CTG ACC AGC CAG TCC AGG-3' (reverse). The PCR amplification consisted of an initial denaturation at $95^{\circ} \mathrm{C}$ for 2 min, followed by 35 cycles at $95^{\circ} \mathrm{C}$ for $30 \mathrm{~s}, 64.5^{\circ} \mathrm{C}$ for $30 \mathrm{~s}$, and $72^{\circ} \mathrm{C}$ for $1 \mathrm{~min}$, and a final extension at $72^{\circ} \mathrm{C}$ for $8 \mathrm{~min}$. The PCR products were analyzed by agarose gel electrophoresis. The amplified fragments were cut from the gel and purified using the PureLink ${ }^{\mathrm{TM}}$ Quick Gel Extraction Kit (Invitrogen) following manufacturer instructions. All PCR products were inserted into a TOPO TA Cloning ${ }^{\mathbb{B}}$ vector (Invitrogen) following manufacturer instructions and were then transformed using DH5 $\alpha$ electrocompetent cells. The recombinant clones were isolated and sequenced on both strands using the M13 universal primers and the BigDye ${ }^{\circledR}$ Terminator v3.1. kit (Applied Biosystems) for the automatic sequencer ABI 3100 (Applied Biosystems). The chromatograms obtained were manually analyzed using the Vector NTI Suite 8 program (InforMax), followed by the removal of the vector sequence (Vector Screen (http://www.ncbi.nlm.nih.gov/VecScreen/VecScreen.html). The global alignment was carried out using ClustalW2 (http://www.ebi.ac.uk/Tools/clustalw2/ index.html) to obtain the consensus sequence. The samples that showed alterations were submitted to a resequencing for confirmation. Finally, the SIFT program (Sorting Intolerant from Tolerant - http://sift.jcvi.org/) was used to estimate the effects that the mutations might have 
on protein structure. The resultant classification was between tolerable and change of function. The alterations were determined based on the results of Ziober et al. (2009) in relation to pattern matching with the new sequence published in GenBank (accession No. GQ337080).

The meat quality was evaluated using the luminosity parameter that was assessed with a Minolta colorimeter CR $400^{\circledR}$ illuminant D65 at a viewing angle of $10^{\circ}$. The lightness values $\left(\mathrm{L}^{*}\right)$ were expressed in the CIELAB color system. The color measurements were performed $24 \mathrm{~h}$ postmortem on the ventral side of the chicken breast meat. Measurements were recorded at three different points per sample and the results are reported as the average of these three values as described in Soares et al. (2002). The L* value was used to classify the meat fillets into three categories: those with $\mathrm{L}^{*}>53$ were classified as PSE, an $\mathrm{L}^{*}$ value $<44$ was analogous to dark, firm, dried meat, and the intermediate values of $\mathrm{L}^{*}$ ranging from 44 to 53 were classified as normal (Soares et al., 2002). These measurements are correlated to the $\mathrm{pH}$ value as shown in Figure 3.

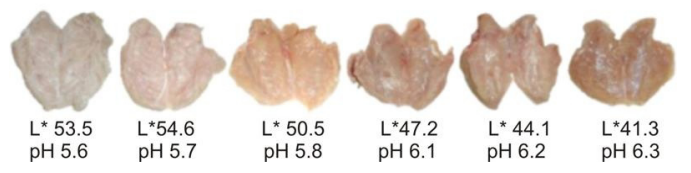

Figure 3. The lightness $\left(\mathrm{L}^{*}\right)$ and $\mathrm{pH}$ values of chicken breast meat (pectoralis major) classified by color: $\mathrm{L}^{*}>53$ denoted PSE, $\mathrm{L}^{*}<44$ is analogous to DFD, and $44 \leq \mathrm{L}^{*} \leq 53$ is considered to be normal meat. PSE $=$ pale, soft, exudative; DFD = dark, firm, dry. Adapted from Oda et al. (2003).

\section{RESULTS AND DISCUSSION}

Heat stress conditions had a major influence on the occurrence of PSE meat, particularly in birds that were exposed to halothane treatment. The common broiler management practice in Brazil follows the sequence of feed and water deprivation, catching, crating, providing water shower before truck transport, transporting and spraying the birds with water on arrival at the processing plant. At each step the birds are subject to stress, and in some cases to heat stress. Figure 4 shows that the incidence of PSE meat was the highest within the H+HS treatment group, with a $66.0 \%$ occurrence of PSE meat. The occurrence of PSE meat was $60.0 \%$ in the HS group, $50.0 \%$ in the $\mathrm{H}$ group, and $33.3 \%$ in the $\mathrm{C}$ group.

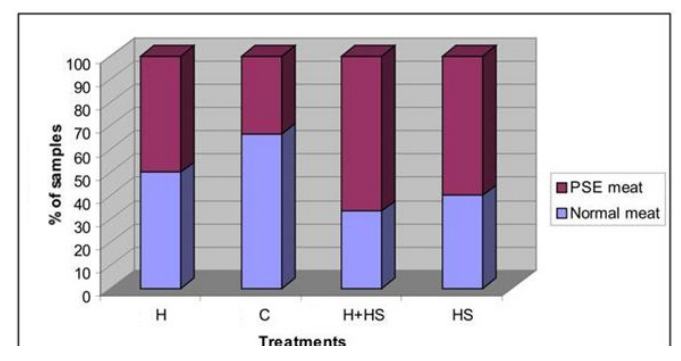

Figure 4. The occurrence of PSE meat taken from broilers in the four different pre-slaughtering treatments. A major PSE (pale, soft, exudative) meat occurrence was observed within the group treated with both halothane and heat stress (H+HS) while a minor occurrence was observed in the control $(\mathrm{C})$ group. $\mathrm{H}=$ halothane-treated group; HS $=$ heat stress without halothane treatment. 
A study was conducted to sequence the hotspot 1 of RYR1 mRNA from all samples collected to detect potential variations by comparative sequencing among chickens that were submitted to the four treatments as described above. The fragments produced from the amplification of the cDNA specific hotspot followed by the electrophoresis gel showed no difference in size between the different treatments. The fragments were exactly the same size (approximately $600 \mathrm{bp}$ ) as those reported by Ziober et al. (2009). In contrast to these results, Chiang et al. (2004) reported three transcripts of different sizes that corresponded to three variants of RyR in turkeys. These variants resulted from base deletions at different locations that resulted in alternative splicing, which in turn led to the deletion of one entire exon. In our case, we found deletions or substitution of only one nucleotide that was related to the detectable differences in the protein structure.

The analyses of the sequences of all 18 samples showed that 10 sequences did not possess any alteration. On the contrary, in the remaining 8 samples, synonymous, tolerable changes and premature stop codons were detected as observed in Table 1.

\begin{tabular}{|c|c|c|c|c|c|c|c|c|}
\hline Sample & Exposure to halothane & Heat stress & Meat quality & Alteration & Nucleotide & Protein & Alteration & Effect on protein \\
\hline $\mathrm{H}+\mathrm{HS} 3$ & Yes & Yes & Normal & Substitution: $\mathrm{T} \rightarrow \mathrm{A}$ & \#12 & \#4 & $\mathrm{L} \rightarrow \mathrm{H}$ & Tolerable \\
\hline H 1 & Yes & No & Normal & $\begin{array}{l}\text { Deletion: } \mathrm{G} \\
\text { Substitution: } \mathrm{G} \rightarrow \mathrm{A}\end{array}$ & $\begin{array}{r}\# 27 \\
\# 363\end{array}$ & \#9 & $\begin{array}{c}\mathrm{G} \rightarrow \mathrm{A}(\mathrm{CRF}) \\
(\# 16) \mathrm{TI}\end{array}$ & Truncated \\
\hline $\mathrm{H}+\mathrm{HS} 5$ & Yes & Yes & PSE & $\begin{array}{l}\text { Substitution: } \mathrm{G} \rightarrow \mathrm{A} \\
\text { Substitution: } \mathrm{A} \rightarrow \mathrm{G}\end{array}$ & $\begin{array}{r}\# 31 \\
\# 443\end{array}$ & \#148 & $\mathrm{T} \rightarrow \mathrm{A}$ & $\begin{array}{l}\text { Synonymous } \\
\text { Tolerable }\end{array}$ \\
\hline $\mathrm{H}+\mathrm{HS} 6$ & Yes & Yes & PSE & $\begin{array}{l}\text { Deletion: } \mathrm{T} \\
\text { Substitution: } A \rightarrow G \\
\text { Substitution: } A \rightarrow G\end{array}$ & $\begin{array}{r}\# 56 \\
\# 305 \\
\# 366\end{array}$ & $\# 19$ & $\begin{array}{c}\mathrm{Y} \rightarrow \mathrm{T}(\mathrm{CRF}) \\
(\# 34) \mathrm{TI}\end{array}$ & Truncated \\
\hline HS 3 & No & Yes & Normal & $\begin{array}{l}\text { Substitution: } \mathrm{T} \rightarrow \mathrm{C} \\
\text { Substitution: } \mathrm{A} \rightarrow \mathrm{G}\end{array}$ & $\begin{array}{l}\# 110 \\
\# 290\end{array}$ & $\begin{array}{l}\# 37 \\
\# 97\end{array}$ & $\begin{array}{l}\mathrm{S} \rightarrow \mathrm{P} \\
\mathrm{I} \rightarrow \mathrm{V}\end{array}$ & $\begin{array}{l}\text { Tolerable } \\
\text { Tolerable }\end{array}$ \\
\hline $\mathrm{C} 3$ & No & No & Normal & $\begin{array}{l}\text { Substitution: } \mathrm{T} \rightarrow \mathrm{C} \\
\text { Substitution: } \mathrm{T} \rightarrow \mathrm{C} \\
\text { Substitution: } \mathrm{C} \rightarrow \mathrm{T}\end{array}$ & $\begin{array}{l}\# 110 \\
\# 275 \\
\# 344\end{array}$ & $\begin{array}{l}\# 37 \\
\# 91\end{array}$ & $\underset{\mathrm{TI}}{\mathrm{S} \rightarrow \mathrm{P}}$ & $\begin{array}{l}\text { Tolerable } \\
\text { Truncated }\end{array}$ \\
\hline H 2 & Yes & No & Normal & $\begin{array}{l}\text { Deletion: } \mathrm{C} \\
\text { Substitution: } \mathrm{T} \rightarrow \mathrm{C}\end{array}$ & $\begin{array}{l}\# 151 \\
\# 352\end{array}$ & $\# 51$ & $\begin{array}{c}\mathrm{I} \rightarrow \mathrm{S}(\mathrm{CRF}) \\
\quad(\# 95) \mathrm{TI}\end{array}$ & Truncated \\
\hline $\mathrm{H}+\mathrm{HS} 4$ & Yes & Yes & PSE & $\begin{array}{l}\text { Deletion: C } \\
\text { Substitution: } \mathrm{T} \rightarrow \mathrm{C}\end{array}$ & $\begin{array}{l}\# 151 \\
\# 352\end{array}$ & $\# 51$ & $\begin{array}{c}\mathrm{I} \rightarrow \mathrm{S}(\mathrm{CRF}) \\
\quad(\# 95) \mathrm{TI}\end{array}$ & Truncated \\
\hline $\mathrm{C} 2$ & No & No & Normal & No alteration & & & & \\
\hline C 1 & No & No & PSE & No alteration & & & & \\
\hline HS 1 & No & Yes & PSE & No alteration & & & & \\
\hline HS 4 & No & Yes & PSE & No alteration & & & & \\
\hline HS 5 & No & Yes & PSE & No alteration & & & & \\
\hline HS 2 & No & Yes & Normal & No alteration & & & & \\
\hline H 3 & Yes & No & PSE & No alteration & & & & \\
\hline H 4 & Yes & No & PSE & No alteration & & & & \\
\hline $\mathrm{H}+\mathrm{HS} 2$ & Yes & Yes & PSE & No alteration & & & & \\
\hline $\mathrm{H}+\mathrm{HS} 1$ & Yes & Yes & Normal & No alteration & & & & \\
\hline
\end{tabular}

According to the results of Chiang et al. (2007), the occurrence of nonsense aRYR mRNAs in turkey transcripts was induced by the heat stress. However, in our results, the higher incidence of nonsense transcripts was related to the exposure of halothane; $80.0 \%$ of nonsense mRNA transcripts that were detected were from the $\mathrm{H}$ and $\mathrm{H}+\mathrm{HS}$ groups. As shown by Marchi 
et al. (2009) halothane treatment itself plays a role as a stressor and therefore may also be a modulating agent for gene expression, as occurred with heat stress. The presence of truncated proteins originated from the deletions of different nucleotides, altered the frame shift, creating a premature stop codon that was the highest in those birds exposed to halothane (Figure 5).

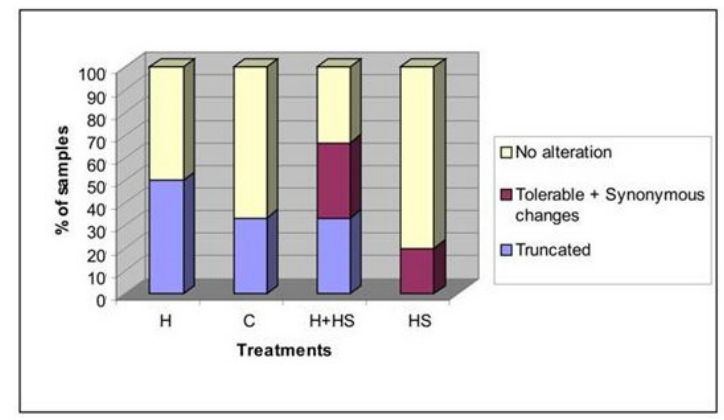

Figure 5. Alterations in the percentage of mRNA detected from the $\alpha$ RYR hotspot 1 in the 18 chicken samples analyzed from a commercial lineage. $\mathrm{H}=$ halothane-treated group; $\mathrm{C}=$ control group; $\mathrm{H}+\mathrm{HS}=$ treated with both halothane and heat stress; HS = heat stress without halothane treatment.

A portion of the RNAs that produced truncated proteins was monitored for errors that were induced during gene expression. The cell possessed a repair mechanism known as the efficient nonsense-mediated mRNA decay pathway. This pathway marks the mRNAs that have premature termination codons (UAA, UAG, UGA) (nonsense); these mRNAs would produce truncated proteins that would consequently degrade faster. The presence of this pathway makes these nonsense mRNAs highly unstable. This mechanism is important because if the defective sequences were to be translated they would produce truncated proteins with the possibility of deleterious functions (Culbertson, 1999; Chang et al., 2007). Another important role of this particular pathway is to control the transcript stability and to regulate the expression of various genes involved in the environmental adaptation through the specific transcript degradation (Régnier and Hajnsdorf, 2009). The RYR1 behaved similarly under the dramatic conditions of the halothane and heat treatments, producing abnormal transcripts.

According to the results reported here, the halothane treatment was somehow able to modulate the $\alpha$ RYR gene expression from the hotspot region and was associated with the heat stress, eventually triggering the development of PSE meat. There is clear evidence that as in the case of PSS there were conditions for the development of Avian Stress syndrome before the formation of PSE meat in broiler chickens. Although a mutation has not been detected in birds, they were prone to alter the RYR1 gene expression performance, thus enhancing the occurrence of meat color abnormalities under heat and halothane treatments. Despite the striking similarities between the muscle biochemical reactions in pork and in avian PSE meat, these results clearly demonstrated that there are genetic differences between species.

\section{CONCLUSIONS}

Heat stress and halothane treatment were found to change the expression pattern of ryanodine receptor transcripts, which in turn affected the postmortem calcium homeostasis and ultimately the meat quality. 


\section{ACKNOWLEDGMENTS}

Research supported by CNPq (Process \#479738/2007-6), Fundação Araucária/ CNPq Pronex (Protocol \#09.277) and Fundação Araucária/Finep under the BioAgroPar Program. We would like to thank CNPq for the graduate scholarship provided to I.L. Ziober. A.L. Nepomuceno, L.L. Coutinho and M. Shimokomaki are recipients of CNPq research fellowships. F.G. Paião is working under a Post-Doctorate CNPq Scholarship Program (Process \#151809/2008-9).

\section{REFERENCES}

Band GO, Guimarães SLF, Lopes PS, Schierholt AS, et al. (2005). Relationship between the Porcine Stress Syndrome gene and pork quality traits of F2 pigs resulting from divergent crosses. Genet. Mol. Biol. 28: 88-91.

Barbut S (1998). Estimating the magnitude of the PSE problem in poultry. J. Muscle Foods 9: 35-49.

Barbut S, Zhang L and Marcone M (2005). Effects of pale, normal, and dark chicken breast meat on microstructure, extractable proteins, and cooking of marinated fillets. Poult. Sci. 84: 797-802.

Barbut S, Sosnicki AA, Lonergan SM, Knapp T, et al. (2008). Progress in reducing the pale, soft and exudative (PSE) problem in pork and poultry meat. Meat Sci. 79: 46-63.

Brini M (2004). Ryanodine receptor defects in muscle genetic diseases. Biochem. Biophys. Res. Commun. 322: 1245-1255.

Chang YF, Imam JS and Wilkinson MF (2007). The nonsense-mediated decay RNA surveillance pathway. Annu. Rev. Biochem. 76: 51-74.

Chiang W, Allison CP, Linz JE and Strasburg GM (2004). Identification of two alphaRYR alleles and characterization of aRYR transcript variants in turkey skeletal muscle. Gene 330: 177-184.

Chiang W, Yoon HJ, Linz JE, Airey JA, et al. (2007). Divergent mechanisms in generating molecular variations of $\alpha$ RYR and betaRYR in turkey skeletal muscle. J. Muscle Res. Cell Motil. 28: 343-354.

Chomczynski P and Sacchi N (1987). Single-step method of RNA isolation by acid guanidinium thiocyanate-phenolchloroform extraction. Anal. Biochem. 162: 156-159.

Culbertson MR (1999). RNA surveillance. Unforeseen consequences for gene expression, inherited genetic disorders and cancer. Trends Genet. 15: 74-80.

Fujii J, Otsu K, Zorzato F, de Leon S, et al. (1991). Identification of a mutation in porcine ryanodine receptor associated with malignant hyperthermia. Science 253: 448-451.

Guarnieri PD, Soares AL, Olivo R, Schneider JP, et al. (2004). Preslaughter handling with water shower spray inhibits PSE (Pale, Soft, Exudative) broiler breast meat in a commercial plant. Biochemical and ultrastructural observations. J. Food Biochem. 28: 269-277.

Langer ROS, Simões GS, Soares AL, Oba A, et al. (2010). Broiler transportation conditions in a Brazilian commercial line and the occurrence of breast PSE (Pale, Soft, Exudative) meat and DFD-like (Dark, Firm, Dry) meat. Braz. Arch. Biol. Technol. (in press).

MacLennan DH (2000). Ca ${ }^{2+}$ signalling and muscle disease. Eur. J. Biochem. 267: 5291-5297.

Marchi DF, Oba A, Ziober IL, Soares AL, et al. (2009). Development of a gas chamber for detecting broiler chicken halothane sensitivity and PSE (Pale, Soft, Exudative) meat formation. Braz. Arch. Biol. Technol. 52: 189-194.

Mitchell MA and Kettlewell PJ (1998). Physiological stress and welfare of broiler chickens in transit: solutions not problems! Poult. Sci. 77: 1803-1814.

Oda SHI, Schneider J, Soares AL, Barbosa DML, et al. (2003). Detecção de cor de filés de peito de frango. Rev. Nac. Carne 27: 30-34.

Oda SHI, Nepomuceno AL, Ledur MC, Oliveira MCN, et al. (2009). Quantitative differential expression of alpha and beta ryanodine receptor genes in PSE (Pale, Soft, Exudative) meat from two chicken lines: broiler and layer. Braz. Arch. Biol. Technol. 52: 1519-1525.

Olivo R and Shimokomaki M (2006). Atualidades em Ciência e Tecnologia de Carnes. In: Carne PSE em Aves (Shimokomaki M, Olivo R, Terra NN and Franco BDGM, eds.). Varela, São Paulo, 95-113.

Olivo R, Soares AL, Ida EI and Shimokomaki M (2001). Dietary vitamin E inhibits poultry PSE and improves meat functional properties. J. Food Biochem. 25: 271-283.

Régnier P and Hajnsdorf E (2009). Poly(A)-assisted RNA decay and modulators of RNA stability. Prog. Mol. Biol. Transl. Sci. 85: 137-185. 
Rossi D and Sorrentino V (2004). The ryanodine receptors gene family: expression and functional meaning. Basic Appl. Myol. 14: 323-343.

Simões GS, Rossa A, Oba A, Matsuo T, et al. (2009a). Transporte e ocorrência de PSE (Pale, Soft, Exudative) e DFD (Dark, Firm, Dry) em filés de peito de frango durante o inverno. Rev. Nac. Carne 23: 20-30.

Simões GS, Oba A, Matsuo T, Rossa A, et al. (2009b). Vehicle thermal microclimate evaluation during Brazilian summer broiler transport and the occurrence of PSE (Pale, Soft, Exudative) meat. Braz. Arch. Biol. Technol. 52 (Special): 195-204.

Soares AL, Lara JAF, Ida EI, Guarnieri PD, et al. (2002). Variation in the Colour of Brazilian Broiler Breast Fillet. In: Proceedings of the 48th International Congress of Meat Science and Technology, 25-30 August Rome, 540-541.

Soares AL, Ida EI, Myiamoto S, Hernández-Blazquez FJ, et al. (2003). Phospholipase A2 activity in poultry PSE, pale, soft, exudative, meat. J. Food Biochem. 27: 309-320.

Soares AL, Marchi DF, Matsushita M, Guarnieri PD, et al. (2009). Lipid oxidation and fatty acid profile related to broiler breast meat color abnormalities. Braz. Arch. Biol. Technol. 52: 1513-1518.

Strasburg GM and Chiang W (2003). Genetic Basis for Pale, Soft and Exudative Turkey Meat. In: Proceedings of the 56th American Meat Science Association, June 15-18, American Meat Science Association, Columbia, 17-22.

Strasburg GM and Chiang W (2009). Pale, soft, exudative turkey - The role of ryanodine receptor variation in meat quality. Poult. Sci. 88: 1497-1505.

Sutko JL and Airey JA (1996). Ryanodine receptor $\mathrm{Ca}^{2+}$ release channels: does diversity in form equal diversity in function? Physiol. Rev. 76: 1027-1071.

Swatland HJ (2008). How pH causes paleness or darkness in chicken breast meat. Meat Sci. 80: 396-400.

Wilhelm AE, Maganhini MB, Hernández-Blazquez FJ, Ida EI, et al. (2010). Protease activity and the ultrastructure of broiler chicken PSE (pale, soft, exudative) meat. Food Chem. 119: 1201-1204.

Ziober IL, Paião FG, Marin SRR, Marchi DF, et al. (2009). Molecular cloning of aRYR hotspot region 1 from broiler chicken. Braz. Arch. Biol. Technol. 52 (Special): 225-231. 